\title{
Effects of Quercetin and Mannitol on Erythropoietin Levels in Rats Following Acute Severe Traumatic Brain Injury
}

\author{
Orhan Kalemci, M.D., ${ }^{1}$ Hasan Emre Aydin, M.D., Ph.D., ${ }^{2,3}$ Ceren Kizmazoglu, M.D., Ismail Kaya, M.D., ${ }^{4}$ Hulya Yılmaz, M.D., ${ }^{5}$ \\ Nuri M Arda, M.D.' \\ Department of Neurosurgery, School of Medicine and Hospital, Dokuz Eylul University, Izmir, Turkey \\ Department of Pharmacology, ${ }^{2}$ Eskisehir Osmangazi University, Eskisehir, Turkey \\ Department of Neurosurgery, ${ }^{3}$ School of Medicine and Hospital, Dumlupınar University, Kutahya, Turkey \\ Department of Neurosurgery, ${ }^{4}$ Kilis State Hospital, Kilis, Turkey \\ Department of Biostatistics and Medical Informatics, ${ }^{5}$ Eskisehir Osmangazi University, Eskisehir, Turkey
}

Objective : The aim of this study to investigate the normal values of erythropoietin (EPO) and neuroprotective effects of quercetin and mannitol on EPO and hematocrit levels after acute severe traumatic brain injury (TBI) in rat model.

Methods : A weight-drop impact acceleration model of TBI was used on 40 male Wistar rats. The animals were divided into sham (group I), TBI (group II), TBI+quercetin (50 mg/kg intravenously) (group III), and TBI+mannitol (1 mg/kg intravenously) (group IV) groups. The malondialdehyde, glutathione peroxidase, catalase, EPO, and hematocrit levels were measured 1 and 4 hour after injury. Two-way repeated measures analysis of variance and Tukey's test were used for statistical analysis.

Results : The malondialdehyde levels decreased significantly after administration of quercetin and mannitol compared with those in group II. Catalase and glutathione peroxidase levels increased significantly in groups III and IV. Serum EPO levels decreased significantly after mannitol but not after quercetin administration. Serum hematocrit levels did not change significantly after quercetin and mannitol administration 1 hour after trauma. However, mannitol administration decreased serum hematocrit levels significantly after 4 hour.

Conclusion : This study suggests that quercetin may be a good alternative treatment for TBI, as it did not decrease the EPO levels.

Key Words : Brain injuries · Traumatic · Quercetin · Mannitol · Erythropoietin · Hematocrit.

\section{INTRODUCTION}

Traumatic brain injury (TBI) is a common cause of death and disability in young people and a major health and socio- economic problem worldwide ${ }^{9,18,32,46)}$. TBI can result in permanent cognitive and motor deficits due to primary and secondary injuries ${ }^{10)}$. Many serum biomarkers have been used to detect the severity of TBI. Glial protein S-100 beta (S100B),

- Received : May 31, 2016 •Revised : October 27, 2016 •Accepted : November 29, 2016

- Address for reprints : Orhan Kalemci, M.D.

Department of Neurosurgery, School of Medicine and Hospital, Dokuz Eylul University, 35340 Inciralti- Izmir, Turkey

Tel : +90-232-4123305, Fax : +90-232-2788802, E-mail : okalemci@gmail.com

This is an Open Access article distributed under the terms of the Creative Commons Attribution Non-Commercial License (http://creativecommons.org/licenses/by-nc/4.0) which permits unrestricted non-commercial use, distribution, and reproduction in any medium, provided the original work is properly cited. 
glial fibrillary acidic protein and ubiquitin C-terminal hydrolase-L1 (UCH-L1) serum levels incerases according to the severity of the $\mathrm{TBI}^{31)}$. Neurological damage occurs mostly from secondary brain injury caused by brain edema, increased intracranial pressure, and decreased cerebral perfusion ${ }^{11)}$. However, no effective treatments are available for the secondary injury except routine medical intervention and care ${ }^{36,38)}$.

Quercetin is a well-known flavonoid found widely in red onions, grapes, apples, berries, cherries, broccoli, citrus, lettuce, chili peppers, tomatoes, apple nuts, tea, potatoes, soybeans, peanuts, and red wine ${ }^{5,22,24)}$. Quercetin can cross the blood-brain barrier (BBB) and has neuroprotective effects on the central nervous system ${ }^{27,40,50)}$. Quercetin also has cardioprotective, antioxidant, anti-inflammatory, anti-apoptotic, anti-tumoral, anti-thrombotic, antiviral, and antidepressant properties $^{5,15,16,21,26,34,44)}$.

Quercetin reduces oxidative stress and lipid peroxidation by increasing catalase (Cat) and glutathione peroxidase (GSH-Px) levels, which have an important roles as antioxidants ${ }^{2,30)}$. Malondialdehyde (MDA) is the endproduct of lipid peroxidation and is a commonly used marker of oxidative stress ${ }^{42)}$.

Mannitol is a hypertonic, hyperosmolar agent commonly used to treat vasogenic, cytotoxic, and interstitial brain ede$\mathrm{ma}^{29)}$. Mannitol also has an antioxidant effect by reducing oxygen free radicals ${ }^{49)}$.

Erythropoietin (EPO) and the EPO receptor (EPOR) play important roles in erythropoiesis and are generally detected in the kidney and liver ${ }^{17)}$. Tissue hypoxia activates EPO, which has antioxidative, anti-inflammatory, anti-apoptotic, neurotrophic, and angiogenic effects ${ }^{47}$. EPO and EPOR are also expressed in the central nervous system, where they have a neuroprotective effect after $\mathrm{TBI}^{1)}$.

Low hematocrit level increases intracranial pressure after traumatic brain injury ${ }^{51)}$. Hematocrit levels should not be lower than $30 \%$ in clinical practice ${ }^{45)}$.

In this study, we investigated the normal EPO values and the neuroprotective effects of quercetin and mannitol on EPO and hematocrit levels after acute severe TBI in a rat model.

\section{MATERIALS AND METHODS}

All experimental procedures and animal care were in accordance with the guidelines of Osmangazi University, Faculty of
Medicine. The experimental protocols used in this study were approved by the Animal Experimental Ethics Committee of Dokuz Eylul University.

A weight-drop impact acceleration model of TBI was used on the rats in this study ${ }^{6,33)}$. Forty male Wistar rats (weight, $318.3 \pm 5$ g) were divided randomly into four groups (n=10/group): group I, sham; group II, TBI; group III, TBI+quercetin (50 mg/kg intravenous); and group IV, TBI+mannitol (1 mg/kg intravenous). The rats were anesthetized intraperitoneally with $100 \mathrm{mg} / \mathrm{kg}$ s-ketamine (Ketanest S; Pfizer, New York, NY, USA) and $10 \mathrm{mg} / \mathrm{kg}$ xylazine (Xylazin 2\%; Medistar, Ascheberg, Germany).

The rats were acclimatized in a suitable environment $\left(21 \pm 2^{\circ} \mathrm{C}\right.$ and $60 \pm 5 \%$ humidity) for 1 week before starting the experiment. The body weight of each rat was determined before surgery. A heating pad and heating lamp were used to maintain a rectal temperature of $36.5-37.5^{\circ} \mathrm{C}$. Rats with a skull fracture, seizure, or nasal bleeding or that did not survive the impact were excluded from the study. All rats were sacrificed at $4 \mathrm{~h}$ after TBI.

Blood $(50 \mu \mathrm{L})$ was collected via a tail vein before injury and 1 and $4 \mathrm{~h}$ after TBI to determine the MDA (R\&D Systems, Minneapolis, MN, USA), Cat (Cusabio Biotec ELISA kit, Wuhan, China), GSH-Px (Cusabio Biotec), and EPO (Sigma Aldrich Chemie GmbH, Steinheim, Germany) levels in serum using enzyme-linked immunoassay kits according to the manufacturer's instructions.

\section{Statistical analysis}

Statistical analyses were performed with the SigmaStat 3.5 package (Systat Software Inc., San Jose, CA, USA). Data are presented as mean \pm standard deviation. A two-way repeatedmeasures analysis of variance (ANOVA) was used to evaluate interactions among the groups, and Tukey's test was used to detect differences between groups and the repeated measures. A $p$-value $<0.05$ was considered significant.

\section{RESULTS}

The MDA levels in groups III and IV were significantly lower than those in group II $(p<0.005)$. The Cat levels were significantly higher in groups III and IV than those in group II $(p<0.001)$ (Table 1). However, no difference in Cat levels was observed between groups III and IV $(p=0.236)$. The GSH-Px levels were significantly higher in groups III and group IV 
Table 1. Statistical analysis of 1 hour after TBI

\begin{tabular}{lcccc}
\hline $\mathbf{1}$ hour & Sham $(\mathbf{n}=\mathbf{1 0})$ & Trauma $(\mathbf{n}=10)$ & Quercetin $(\mathbf{n}=\mathbf{1 0})$ & Mannitol $(\mathbf{n}=\mathbf{1 0})$ \\
\hline MDA $(\mathrm{ng} / \mathrm{L})$ & $4.71 \pm 0.41$ & $10.38 \pm 1.15$ & $6.71 \pm 0.44^{*}$ & $5.84 \pm 0.78^{*}$ \\
Catalase $(\mathrm{ng} / \mathrm{mL})$ & $18.38 \pm 2.70$ & $8.63 \pm 1.73$ & $10.40 \pm 1.62^{\dagger}$ & $12.50 \pm 2.76^{\dagger}$ \\
GSH-Px $(\mathrm{pmol} / \mathrm{mL})$ & $61.90 \pm 6.65$ & $41.10 \pm 2.79$ & $54.00 \pm 6.60^{\ddagger}$ & $52.70 \pm 12.44^{\ddagger}$ \\
EPO (OD: $450 \mathrm{~nm})$ & $1.70 \pm 0.34$ & $3.80 \pm 0.44$ & $2.80 \pm 0.72$ & $2.40 \pm 0.66^{5}$ \\
HTC (\%) & $4.21 \pm 0.41$ & $2.80 \pm 0.82$ & $2.17 \pm 0.17$ & $1.85 \pm 0.31$ \\
\hline
\end{tabular}

${ }^{*}$ MDA levels were significantly lower than group $\|(p<0.05) .{ }^{\dagger}$ Catalase levels were significantly higher than group $\|(p<0.05) .{ }^{\ddagger} \mathrm{GSH}-\mathrm{Px}$ levels

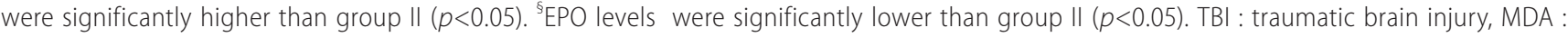
malondialdehyde, GSH-Px: glutathione peroxidase, EPO : erythropoietin, HTC : hematocrit

Table 2. Statistical analysis of 4 hour after TBI

\begin{tabular}{lcccc}
\hline 4 hour & Sham $(\mathbf{n}=10)$ & Trauma $(\mathbf{n}=10)$ & Quercetin $(\mathbf{n}=10)$ & Mannitol $(\mathbf{n}=10)$ \\
MDA $(\mathrm{ng} / \mathrm{L})$ & $4.23 \pm 0.81$ & $10.75 \pm 1.57$ & $7.80 \pm 1.52^{*}$ & $6.43 \pm 1.95^{*}$ \\
Catalase $(\mathrm{ng} / \mathrm{mL})$ & $18.55 \pm 1.56$ & $9.40 \pm 0.66$ & $12.40 \pm 0.96^{\dagger}$ & $11.90 \pm 2.55^{\dagger}$ \\
GSH-Px $(\mathrm{pmol} / \mathrm{mL})$ & $62.20 \pm 6.13$ & $45.60 \pm 6.21$ & $49.90 \pm 7.37^{\ddagger}$ & $47.20 \pm 6.91^{\ddagger}$ \\
EPO (OD: $450 \mathrm{~nm})$ & $1.50 \pm 0.44$ & $3.20 \pm 0.54$ & $3.00 \pm 0.50$ & $2.10 \pm 0.40^{\S}$ \\
HTC (\%) & $4.01 \pm 1.29$ & $3.65 \pm 0.94$ & $3.50 \pm 0.93$ & $2.40 \pm 0.30^{\prime \prime}$ \\
\hline
\end{tabular}

${ }^{*}$ MDA levels were significantly lower than group II $(p<0.05) .{ }^{\dagger}$ Catalase levels were significantly higher than group II $(p<0.05)$. ${ }^{\ddagger} \mathrm{GSH}-\mathrm{Px}$ levels were significantly higher than group II $(p<0.05)$. ${ }^{\varsigma} E P O$ levels were significantly lower than group II $(p<0.05)$. "HTC levels are were significantly lower than group II $(p<0.05)$. TBI : traumatic brain injury, MDA : malondialdehyde, GSH-Px : glutathione peroxidase, EPO : erythropoietin, HTC : hematocrit

than those in group II after TBI $(p<0.005)$ (Table 2). Quercetin more effective on GPH-Px levels compared with that of mannitol but there was no significant difference $(p<0.152)$ (Fig. 1).

The serum EPO level in group II increased compared with that in group I. No differences were detected between the Cat ( $p=0.576)$ and GSH-Px $(p=1.415)$ levels 1 and $4 \mathrm{~h}$ after TBI. Quercetin tended to decrease the EPO levels ( $p=0.102$ ), whereas mannitol significantly decreased the serum EPO levels $(p<0.005)$. Our data revealed that administering quercetin after TBI did not negatively change the EPO levels, whereas mannitol lowered them significantly. Serum hematocrit did not change significantly $1 \mathrm{~h}$ after TBI in response to quercetin ( $p=0.170)$ or mannitol $(p=0.130)$ administration. However, mannitol decreased serum hematocrit significantly $4 \mathrm{~h}$ after TBI $(p<0.05)$ because mannitol has an osmotic effect on blood plasma (Fig. 2). These results indicate that mannitol, but not quercetin, changed the serum EPO levels after TBI.

\section{DISCUSSION}

TBI is a pathological condition with debilitating and possibly lethal features as a result of primary and secondary damage. Brain swelling has an important role in secondary brain injury, as it results in increased intracranial pressure and decreased cerebral perfusion leading to neuronal death ${ }^{11}$. Several drugs, such as antioxidants and calcium channel blockers, have been developed to prevent the secondary injury caused by TBI; however, none are clinically effective.

A weakness of our study is that we studied biochemical parameters in blood. Some authors studied biochemical parameters in traumatic brain tissue ${ }^{44,49}$. Hematocrit normally increases within 2 weeks and returns to normal within 6 weeks after trauma ${ }^{13,35)}$. Hematocrit changes drastically after a massive blood loss, dehydration, or hyper-hydration in patients suffering from acute traumatic injury.

The proposed neuroprotective effect of quercetin is that it directly decreases oxidative stress and iron-mediated lipid peroxidation and inhibits myeloperoxidase activity and the apoptotic pathways ${ }^{12)}$. Few studies have reported the levels of 

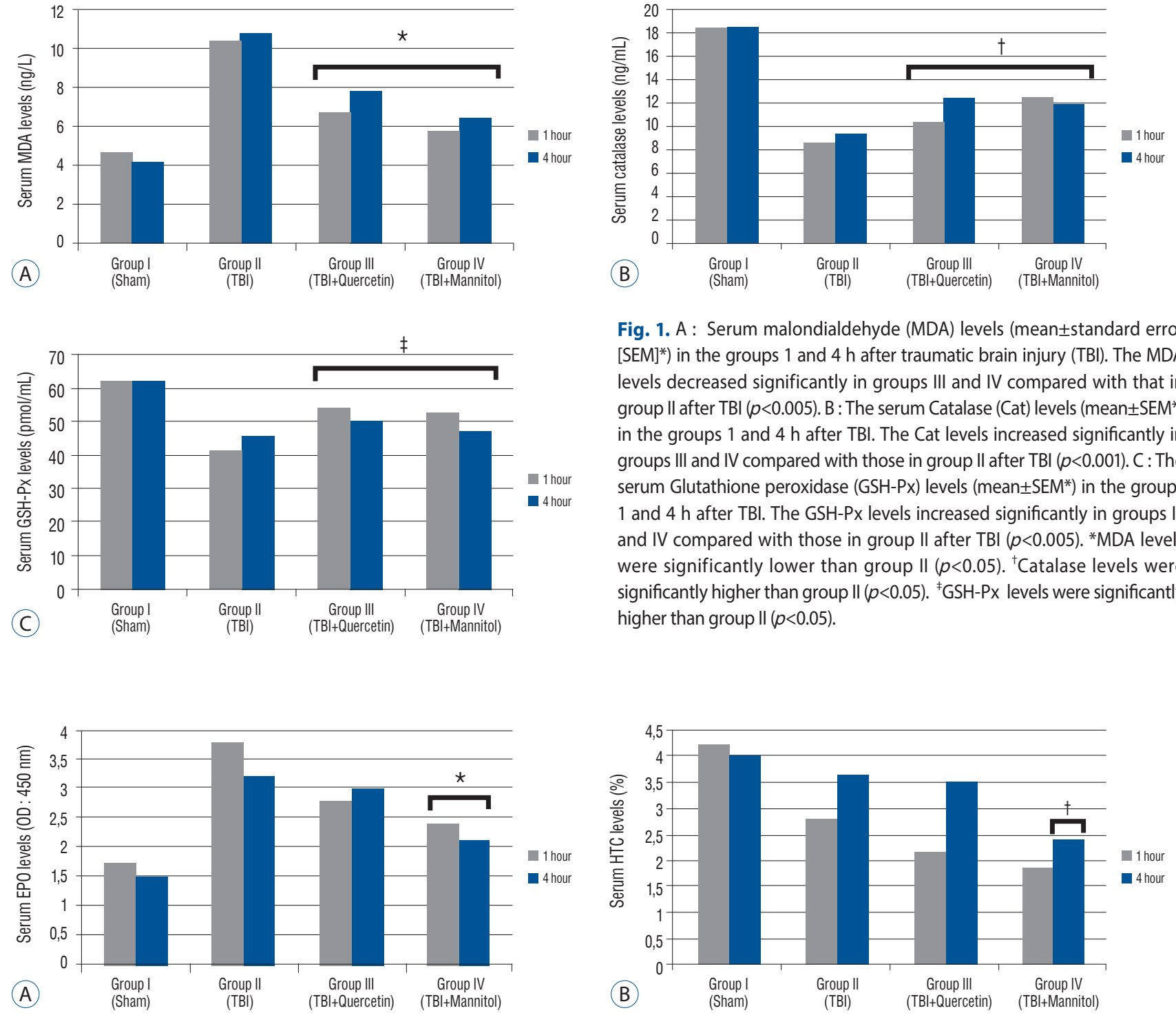

Fig. 2. A : Serum erythropoietin (EPO) levels (means \pm standard error [SEM]*) in the groups 1 and $4 \mathrm{~h}$ after traumatic brain injury (TBI). The serum EPO level tended to decrease in group III compared with that in group I after TBI $(p=0.102)$. The serum EPO levels decreased significantly in group IV compared with that in group I after TBI $(p<0.005)$. B : The hematocrit (HTC) levels (mean \pm SEM*) in the groups 1 and $4 \mathrm{~h}$ after TBI. The serum HTC levels decreased significantly in group IV $4 \mathrm{~h}$ after TBI $(p<0.05)$. ${ }^{*}$ EPO levels were significantly lower than group II $(p<0.05)$. ${ }^{\dagger} H T C$ levels are were significantly lower than group II $(p<0.05)$.

GSH-Px, Cat, and MDA after administration of quercetin and mannitol in cases of TBI.

Quercetin has a neuroprotective effect by increasing GSHPx and decreasing the MDA levels after subarachnoid hemorrhage in rats. In our study, quercetin increased the GSH-Px and Cat levels but significantly decreased the MDA level.

Schültke et al. reported that quercetin prevented the decrease in glutathione and MDA after fluid percussion injury

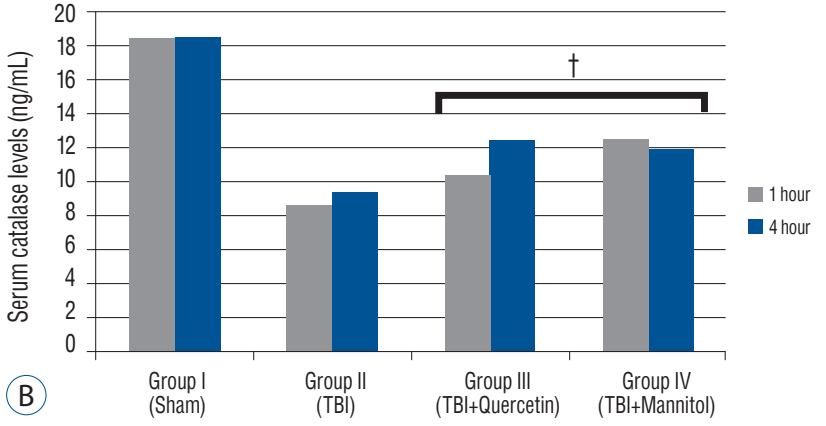

Fig. 1. A : Serum malondialdehyde (MDA) levels (mean \pm standard error [SEM]*) in the groups 1 and $4 \mathrm{~h}$ after traumatic brain injury (TBI). The MDA levels decreased significantly in groups III and IV compared with that in group II after TBI $(p<0.005)$. B : The serum Catalase (Cat) levels (mean \pm SEM*) in the groups 1 and $4 \mathrm{~h}$ after TBI. The Cat levels increased significantly in groups III and IV compared with those in group II after TBI $(p<0.001)$. C : The serum Glutathione peroxidase (GSH-Px) levels (mean \pm SEM*) in the groups 1 and $4 \mathrm{~h}$ after TBI. The GSH-Px levels increased significantly in groups III and IV compared with those in group II after TBI $(p<0.005)$. *MDA levels were significantly lower than group II $(p<0.05) .{ }^{\dagger}$ Catalase levels were significantly higher than group II $(p<0.05)$. ${ }^{\ddagger} \mathrm{GSH}-\mathrm{Px}$ levels were significantly higher than group II $(p<0.05)$. in a rat model $^{44)}$. In the present study, quercetin was more effective than mannitol on MDA and GSH-Px levels in the rat drop-weight model. Ossola et al. reported that quercetin did not cross the BBB; however, other studies have demonstrated that it does cross the $\mathrm{BBB}^{14,37)}$. Mannitol can cross and disrupt the $\mathrm{BBB}$, which helps other drugs to cross the BBB. However, the BBB is often damaged after TBI, which can allow other drugs to cross the BBB as well. Low-dose mannitol provides 
improved the efficiency of quercetin in our study and could be used in a combined treatment with quercetin in future studies. Quercetin may increase antioxidant enzyme activities (GSH-Px and Cat) and improve cognitive function after $\mathrm{TBI}^{48)}$. Our study demonstrated that quercetin activated antioxidant enzymes and reduced lipid peroxidation.

Mannitol and hypertonic saline increase Cat and GSH-Px levels; thus reducing the MDA level ${ }^{49)}$. In the present study, mannitol lowered MDA and increased GSH-Px and Cat levels immediately after TBI, but quercetin had more of an effect on MDA and GSH-Px levels than did mannitol.

Preclinical studies have shown that EPO protects against neurological injury in several in vitro and in vivo experimental models ${ }^{19,20,28,41)}$. In our study, the EPO levels increased after trauma, presumably to promote neuroprotection, but quercetin and mannitol decreased the EPO levels. Further, no differences in the EPO levels were observed between the groups after quercetin or mannitol administration. We demonstrated that mannitol reduced the EPO levels after TBI. Basarslan et al. found that EPO reduced tissue MDA levels and increased GSH-Px activity in a group that received EPO. They concluded that saline and dextran had no effect on lipid peroxidation in an experimental rat drop-weight model ${ }^{4)}$. Quercetin and mannitol also reduced the MDA level and increased GSH-Px activity for neuroprotection, similar to EPO. Administering EPO and maintaining hemoglobin $>10 \mathrm{~g} / \mathrm{dL}$ in patients with TBI did not result in neurobehavioral improvement, but neurological improvement occurred after 6 months ${ }^{41}$. Peng et al. reported that EPO helped to treat experimental TBI by reducing lesion volume and improving neurological outcome ${ }^{39)}$.

Administering EPO to rats with traumatic axonal injury increased the expression of EPOR, which plays an important role in neuroprotection ${ }^{25}$. Schober et al. reported that EPO inhibited caspase-dependent apoptosis and improved neurobehavioral outcomes early after a controlled cortical im$\operatorname{pact}^{43)}$.

One study administered EPO 30 min after diffuse impactacceleration and evaluated the animal $2 \mathrm{~h}$ later ${ }^{8}$. They found that brain hypoxia and cell edema were reversed by recombinant human EPO. Hartley et al. demonstrated that EPO increased extracellular glucose levels and decreased lactate and pyruvate levels after acute TBI in a rat model, which maintained the energy requirements of the brain ${ }^{23)}$. In our study, we showed a neuroprotective effect of EPO in an acute severe rat TBI model.

EPO significantly increases hematocrit in the long term after TBI. Zhang et al. reported that an increased hematocrit level did not affect the neuroprotective or neurorestorative effects of EPO in rats after TBI, suggesting that the effect of EPO was independent of hematocrit ${ }^{51}$. Balak et al. demonstrated that serum osmolarity decreased during the first $3 \mathrm{~h}$ after $\mathrm{TBI}^{3)}$. We failed to show a significant role of hematocrit as an independent parameter, and quercetin had no effect on hematocrit. Hematocrit levels did not change $1 \mathrm{~h}$ after TBI, but decreased after $4 \mathrm{~h}$ in group IV, possibly because of the osmotic effect of mannitol on blood plasma.

\section{CONCLUSION}

No study has investigated the effects of quercetin or mannitol on the serum EPO levels. In our study, mannitol, but not quercetin, changed the serum EPO levels after TBI. This study suggests that quercetin may be a good alternative treatment for TBI.

\section{References}

1. Akdemir Ozisik P, Oruckaptan H, Ozdemir Geyik P, Misirlioglu M, Sargon $M F$, Kilinc $K$, et al. : Effect of erythropoietin on brain tissue after experimental head trauma in rats. Surg Neurol 68 : 547-555; discussion 555, 2007

2. Ansari MA, Abdul HM, Joshi G, Opii WO, Butterfield DA : Protective effect of quercetin in primary neurons against Abeta(1-42): relevance to Alzheimer's disease. J Nutr Biochem 20 : 269-275, 2009

3. Balak N, Isiksacan $N$, Turkoglu R : Does serum osmolarity change as a result of the reflex neuroprotective mechanism of cerebral osmo-regulation after minor head trauma? J Korean Neurosurg Soc 45 : 151-156, 2009

4. Basarslan SK, Gocmez C, Kamasak K, Ekici MA, Ulutabanca H, Dogu Y, et al. : The effects of erythropoietin, dextran and saline on brain edema and lipid peroxidation in experimental head trauma. Ulus Travma Acil Cerrahi Derg 21 : 235-240, 2015

5. Bischoff SC : Quercetin: potentials in the prevention and therapy of disease. Curr Opin Clin Nutr Metab Care 11 : 733-740, 2008

6. Blaha M, Schwab J, Vajnerova O, Bednar M, Vajner L, Michal T : Intracranial pressure and experimental model of diffuse brain injury in rats. J Korean Neurosurg Soc 47 : 7-10, 2010

7. Bleilevens C, Roehl AB, Goetzenich A, Zoremba N, Kipp M, Dang J, et al. : Effect of anesthesia and cerebral blood flow on neuronal injury in a rat 
middle cerebral artery occlusion (MCAO) model. Exp Brain Res 224 : 155-164, 2013

8. Bouzat P, Millet A, Boue Y, Pernet-Gallay K, Trouve-Buisson T, GaideChevronnay $L$, et al. : Changes in brain tissue oxygenation after treatment of diffuse traumatic brain injury by erythropoietin. Crit Care Med 41 : 1316-1324, 2013

9. Cole TB : Global road safety crisis remedy sought: 1.2 million killed, 50 million injured annually. JAMA 291 : 2531-2532, 2004

10. Davis AE : Mechanisms of traumatic brain injury: biomechanical, structural and cellular considerations. Crit Care Nurs Q $23: 1-13,2000$

11. DeWitt DS, Jenkins LW, Prough DS : Enhanced vulnerability to secondary ischemic insults after experimental traumatic brain injury. New Horiz 3 : 376-383, 1995

12. Dong YS, Wang $J$, Feng DY, Qin HZ, Wen H, Yin ZM, et al. : Protective effect of quercetin against oxidative stress and brain edema in an experimental rat model of subarachnoid hemorrhage. Int J Med Sci 11 : 282-290, 2014

13. Dugas AJ Jr, Castaneda-Acosta J, Bonin GC, Price KL, Fischer NH, Winston GW : Evaluation of the total peroxyl radical-scavenging capacity of flavonoids: structure-activity relationships. J Nat Prod 63 : 327-331, 2000

14. Faria A, Pestana D, Teixeira D, Azevedo J, De Freitas V, Mateus N, et al. : Flavonoid transport across RBE4 cells: a blood-brain barrier model. Cell Mol Biol Lett 15 : 234-241, 2010

15. Fernandez SP, Wasowski C, Loscalzo LM, Granger RE, Johnston GA, Paladini AC, et al. : Central nervous system depressant action of flavonoid glycosides. Eur J Pharmacol 539 : 168-176, 2006

16. Ferrali M, Signorini C, Ciccoli L, Bambagioni S, Rossi V, Pompella A, et al. : Protection of erythrocytes against oxidative damage and autologous immunoglobulin $\mathrm{G}(\mathrm{lg} \mathrm{G}$ ) binding by iron chelator fluor-benzoil-pyridoxal hydrazone. Biochem Pharmacol 59 : 1365-1373, 2000

17. Fisher JW : Erythropoietin: physiology and pharmacology update. Exp Biol Med (Maywood) $228: 1-14,2003$

18. Ghajar I : Traumatic brain injury. Lancet 356 : 923-929, 2000

19. Grasso G, Alafaci C, Buemi M. Erythropoietin in traumatic brain injury: an answer will come soon. World Neurosurg 84 : 1491-1492, 2015

20. Grasso G, Sfacteria A, Meli F, Fodale V, Buemi M, lacopino DG : Neuroprotection by erythropoietin administration after experimental traumatic brain injury. Brain Res 1182 : 99-105, 2007

21. Haleagrahara N, Radhakrishnan A, Lee N, Kumar $P$ : Flavonoid quercetin protects against swimming stress-induced changes in oxidative biomarkers in the hypothalamus of rats. Eur J Pharmacol 621 : 46-52, 2009

22. Harnly JM, Doherty RF, Beecher GR, Holden JM, Haytowitz DB, Bhagwat $\mathrm{S}$, et al. : Flavonoid content of U.S. fruits, vegetables, and nuts. J Agric Food Chem 54 : 9966-9977, 2006

23. Hartley CE, Varma M, Fischer JP, Riccardi R, Strauss JA, Shah S, et al. : Neuroprotective effects of erythropoietin on acute metabolic and pathological changes in experimentally induced neurotrauma. J Neurosurg 109 : 708-714, 2008

24. Havsteen $\mathrm{BH}$ : The biochemistry and medical significance of the flavonoids. Pharmacol Ther 96 : 67-202, 2002
25. Hellewell SC, Yan EB, Alwis DS, Bye N, Morganti-Kossmann MC : Erythropoietin improves motor and cognitive deficit, axonal pathology, and neuroinflammation in a combined model of diffuse traumatic brain injury and hypoxia, in association with upregulation of the erythropoietin receptor. J Neuroinflammation 10 : 156, 2013

26. Hertog MG, Feskens EJ, Hollman PC, Katan MB, Kromhout D : Dietary antioxidant flavonoids and risk of coronary heart disease: the Zutphen Elderly Study. Lancet 342 : 1007-1011, 1993

27. Jager AK, Saaby L : Flavonoids and the CNS. Molecules 16 : 14711485,2011

28. Juul SE, Beyer RP, Bammler TK, McPherson RJ, Wilkerson J, Farin FM : Microarray analysis of high-dose recombinant erythropoietin treatment of unilateral brain injury in neonatal mouse hippocampus. Pediatr Res 65 : 485-492, 2009

29. Kaufmann AM, Cardoso ER : Aggravation of vasogenic cerebral edema by multiple-dose mannitol. J Neurosurg 77 : 584-589, 1992

30. Kook D, Wolf AH, Yu AL, Neubauer AS, Priglinger SG, Kampik A, et al. : The protective effect of quercetin against oxidative stress in the human RPE in vitro. Invest Ophthalmol Vis Sci 49 : 1712-1720, 2008

31. Lee JY, Lee CY, Kim HR, Lee CH, Kim HW, Kim JH : A role of serumbased neuronal and glial markers as potential predictors for distinguishing severity and related outcomes in traumatic brain injury. J Korean Neurosurg Soc 58 : 93-100, 2015

32. Maas Al, Stocchetti $N$, Bullock $R$ : Moderate and severe traumatic brain injury in adults. Lancet Neurol $7:$ 728-741, 2008

33. Marmarou A, Foda MA, van den Brink W, Campbell J, Kita H, Demetriadou $\mathrm{K}$ : A new model of diffuse brain injury in rats. Part I: Pathophysiology and biomechanics. J Neurosurg 80 : 291-300, 1994

34. Middleton E Jr, Kandaswami C, Theoharides TC : The effects of plant flavonoids on mammalian cells: implications for inflammation, heart disease, and cancer. Pharmacol Rev 52 : 673-751, 2000

35. Myhrstad MC, Carlsen H, Nordstrom O, Blomhoff R, Moskaug JO : Flavonoids increase the intracellular glutathione level by transactivation of the gamma-glutamylcysteine synthetase catalytical subunit promoter.

Free Radic Biol Med 32 : 386-393, 2002

36. Narayan RK, Michel ME, Ansell B, Baethmann A, Biegon A, Bracken MB, et al. : Clinical trials in head injury. J Neurotrauma 19 : 503-557, 2002

37. Ossola B, Kaariainen TM, Mannisto PT : The multiple faces of quercetin in neuroprotection. Expert Opin Drug Saf 8 : 397-409, 2009

38. Park JE, Kim SH, Yoon SH, Cho KG, Kim SH : Risk factors predicting unfavorable neurological outcome during the early period after traumatic brain injury. J Korean Neurosurg Soc 45 : 90-95, 2009

39. Peng W, Xing Z, Yang J, Wang Y, Wang W, Huang W : The efficacy of erythropoietin in treating experimental traumatic brain injury: a systematic review of controlled trials in animal models. J Neurosurg 121 : 653-664, 2014

40. Rangel-Ordonez L, Noldner $M$, Schubert-Zsilavecz $M$, Wurglics $M$ : Plasma levels and distribution of flavonoids in rat brain after single and repeated doses of standardized Ginkgo biloba extract EGb $761^{\circledR}$ Planta Med 76 : 1683-1690, 2010

41. Robertson CS, Hannay HJ, Yamal JM, Gopinath S, Goodman JC, Tilley 
BC, et al. : Effect of erythropoietin and transfusion threshold on neurological recovery after traumatic brain injury: a randomized clinical trial.

JAMA 312 : 36-47, 2014

42. Rossi R, Dalle-Donne I, Milzani A, Giustarini D : Oxidized forms of glutathione in peripheral blood as biomarkers of oxidative stress. Clin Chem 52 : 1406-1414, 2006

43. Schober ME, Requena DF, Block B, Davis LJ, Rodesch C, Casper TC, et al. : Erythropoietin improved cognitive function and decreased hippocampal caspase activity in rat pups after traumatic brain injury. J Neurotrauma $31: 358-369,2014$

44. Schültke E, Kamencic H, Zhao M, Tian GF, Baker AJ, Griebel RW, et al. : Neuroprotection following fluid percussion brain trauma: a pilot study using quercetin. J Neurotrauma 22 : 1475-1484, 2005

45. Tango HK, Schmidt AP, Mizumoto N, Lacava M, Cruz RJ Jr, Auler JO Jr : Low hematocrit levels increase intracranial pressure in an animal model of cryogenic brain injury. J Trauma 66 : 720-726, 2009

46. Thurman D, Guerrero J : Trends in hospitalization associated with traumatic brain injury. JAMA 282 : 954-957, 1999
47. Velly L, Pellegrini L, Guillet B, Bruder N, Pisano P : Erythropoietin 2nd cerebral protection after acute injuries: a double-edged sword? Pharmacol Ther $128:$ 445-459, 2010

48. Yang T, Kong B, Gu JW, Kuang YQ, Cheng L, Yang WT, et al. : Antiapoptotic and anti-oxidative roles of quercetin after traumatic brain injury. Cell Mol Neurobiol 34 : 797-804, 2014

49. Yilmaz N, Dulger H, Kiymaz N, Yilmaz C, Gudu BO, Demir I : Activity of mannitol and hypertonic saline therapy on the oxidant and antioxidant system during the acute term after traumatic brain injury in the rats. Brain Res 1164 : 132-135, 2007

50. Youdim KA, Dobbie MS, Kuhnle G, Proteggente AR, Abbott NJ, RiceEvans $C$ : Interaction between flavonoids and the blood-brain barrier: in vitro studies. J Neurochem 85 : 180-192, 2003

51. Zhang Y, Xiong Y, Mahmood A, Meng Y, Qu C, Schallert T, et al. : Therapeutic effects of erythropoietin on histological and functional outcomes following traumatic brain injury in rats are independent of hematocrit. Brain Res 1294 : 153-64, 2009 